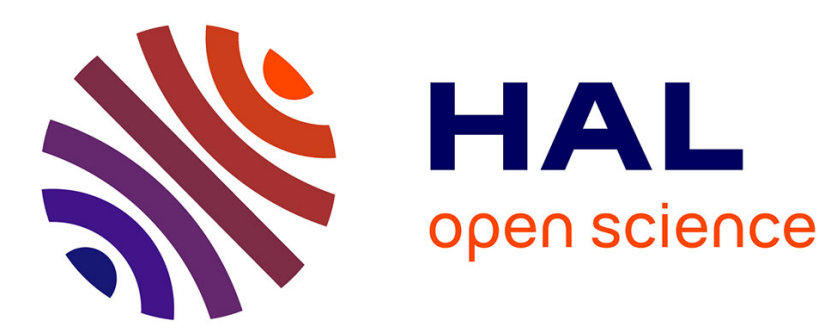

\title{
Direct control based on sliding mode techniques for multicell serial chopper
}

\author{
Leonardo Amet, Malek Ghanes, Jean-Pierre Barbot
}

\section{To cite this version:}

Leonardo Amet, Malek Ghanes, Jean-Pierre Barbot. Direct control based on sliding mode techniques for multicell serial chopper. IEEE ACC (American Control Conference), Jun 2011, San Francisco, United States. hal-00654246

\section{HAL Id: hal-00654246 https://hal.inria.fr/hal-00654246}

Submitted on 22 Dec 2011

HAL is a multi-disciplinary open access archive for the deposit and dissemination of scientific research documents, whether they are published or not. The documents may come from teaching and research institutions in France or abroad, or from public or private research centers.
L'archive ouverte pluridisciplinaire HAL, est destinée au dépôt et à la diffusion de documents scientifiques de niveau recherche, publiés ou non, émanant des établissements d'enseignement et de recherche français ou étrangers, des laboratoires publics ou privés. 


\title{
Direct control based on sliding mode techniques for multicell serial chopper
}

\author{
L. Amet, M. Ghanes and J. P. Barbot
}

\begin{abstract}
Series multi-cell converters introduced more than ten years ago provide many degrees of freedom like the possibility to distribute the voltage constraints among series-connected switches and to improve the output waveforms. Direct control laws make perfect use of them during transient behaviors, but leads to disorderly and imperfect steady-state operations. This paper deals with some solutions for the direct control of the voltages across the flying capacitors in the presence of fast variation of the input voltage by reach an optimal steady-state trajectory defined by the PWM control technique.
\end{abstract}

\section{INTRODUCTION}

The power electronics [1] are well known important technological developments. This is carried out thanks to the developments of power semiconductors and new energy conversion systems. To assume the increase of power consumption, inverters have to be controlled more efficiently and increase their power. A solution to obtain both conditions is to use multilevel inverters [2] which combines switching frequency capability and reduce stress voltage on the power switches [3]. The use of multicellular converters which uses floating capacitors offers additional advantages as low switching ripple, few conduction losses (better energetically switching), small $\mathrm{dV} / \mathrm{dt}$ and modularity of the topologies. These qualities make this new topology very attractive in many industrial applications. For instance, GEC/ACEC implements this proposal to realize the input converter which supplies their "T13" locomotives in power. Three-phase inverters called "symphony" developed by Alstom for driving electric motors are also based on the same principle. However the flying capacitors of this converter must be carefully controlled since the survival of the converter depends on it. Various researches [2], [4] guarantee natural balancing of the flying voltages with a simple open-loop control under certain conditions. The natural balancing operation of the series p-cell converter is obtained when the voltages are close to the multiple of $E / p$ where $E$ is the source voltage and $p$ the number of cells. Nevertheless, in this case, the dynamics involved in the balancing transient depend on the impedance of load at the switching frequency. If the impedance at the switching frequency is high (small current harmonic at this frequency) then the natural balancing is very slow and inversely. This fact has allowed the development of solutions based on an extra "balance booster" which is a simple RLC circuit whose natural frequency equals the switching frequency [5]. Other solutions based on input-output linearization control can be

L. Amet, M. Ghanes and J-P. Barbot are with ECS-Lab ENSEA of Cergy_Pontoise France, \{Leonardo.Amet, Ghanes, Barbot\} densea. fr

J-P. Barbot is also with the EPI-ALIEN-INRIA. found in [6]. However, although the dynamics of rebalancing are really improved, they may still be too slow to follow fast variations of the input voltage and they are not very robust against load variations.

This paper is organized as follows: Section II recalls the mathematical model and PWM control of multicell chopper. In Section III, the proposed direct control based on sliding mode techniques is presented. This control allows to follow rapid variations of the input with good properties in steady state conditions under load variations. Simulation and experimental results are illustrated in section IV to highlight the applicability of the proposed control. Finally, some concluding remarks are given in the last section.

\section{MATHEMATICAL MODEL AND PWM CONTROL FOR MULTICELL CHOPPER}

\section{A. Multicell chopper description}

The multicell structure is based on the implementation of series switching cells (pairs of complementary switches), between which a floating voltage source is inserted. These voltage sources are realized by floating capacitors.

This structure can operate in several configurations: chopper or inverter, implemented as a half or full-bridge.

Figure 1 shows the schematic of an $N$ levels series multicellular converter, consisting on $n=N-1$ cells.

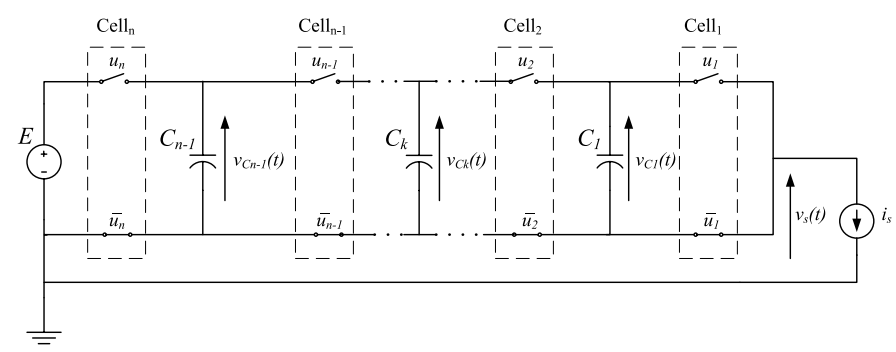

Fig. 1. $n$ cells multicell series converter

The purpose of this paper is to present a sliding mode based control law in order to achieve a balance of internal capacitor voltages described by the following expression:

$$
V_{C_{k}}=k \frac{E}{n}
$$

1) Cell voltages: Under each cell there are 2 floating capacitor voltages: $V_{C_{k}}$ and $V_{C_{k-1}}$, with $V_{C_{0}}=0$ and $V_{C_{n}}=E$. Then

$$
V_{C e l l_{k}}=V_{C_{k}}-V_{C_{k-1}} \text {. }
$$


Under equilibrium conditions (eq.(1)) the cell voltages take the same value:

$$
V_{\text {Cell }_{k}}=\frac{E}{n} .
$$

2) Capacitors and output voltages: The output voltage $v_{s}$ is a function of the $n$ cells switch positions.

$$
v_{s}=\sum_{k=1}^{n} v_{\bar{u}_{k}}=\sum_{k=1}^{n} u_{k} v_{\text {cell }}
$$

In the particular case where the $n$ cell voltages are identical, the output voltage can be expressed as

$$
v_{s}=\frac{E}{n} \sum_{k=1}^{n} u_{k}
$$

The evolution of the capacitor voltages is a function of their flowing current:

$$
\begin{aligned}
i_{C_{k}} & =i_{s}\left(u_{k+1}-u_{k}\right) \\
v_{C_{k}}(t) & =v_{C_{k}}(0)+\int_{0}^{t} \frac{i_{C_{k}}}{C_{k}} d t
\end{aligned}
$$

In equation 5 it can be seen that, for a given output voltage, no matter what switches are closed, just how much of them. This means that the capacitor voltages can be controlled independently of the output voltage (see III-A).

\section{B. PWM control for multicell chopper: brief recall}

Despite the good internal properties of the multicell chopper described in introduction, it is preferable to improve the convergence dynamics to the equilibrium condition without adding the dissipative elements. To do this, the capacitor voltages $V_{C_{k}}$ must be controlled by modifying the different duty cycles $\alpha_{k}$. For more details, this method of control is developed in [7] where the voltages $V_{C_{k}}$ and the load current $I_{s}$ are measured and the following average model is used

$$
\begin{aligned}
\dot{V}_{C_{k}} & =\frac{I_{C_{k}}}{C_{k}}=i_{s}\left(\alpha_{k+1}-\alpha_{k}\right) \\
V_{s} & =\alpha_{n} E+\sum_{k=1}^{n-1} V_{C_{k}}\left(\alpha_{k}-\alpha_{k+1}\right)
\end{aligned}
$$

The convergence to the equilibrium allowed by this control is faster and less oscillatory than natural response. However it is based on the average model and the dynamics of balancing remains slow. That is why we propose in this article a new control allowing the converter to follow fast variations of the input and to have good properties in steady state conditions. This control is based on the instantaneous model which is described in the following.

\section{Instantaneous model}

This model takes into account the instantaneous states of the system (switch positions and capacitor voltages). The dynamic of the $C_{k}$ capacitor is given by:

$$
\frac{d v_{C_{k}}}{d t}(t)=\frac{i_{C_{k}}(t)}{C_{k}}=\frac{\left[u_{k+1}(t)-u_{k}(t)\right]}{C_{k}} i_{s}(t)
$$

The output voltage can be calculated by applying the second Kirchoff's law. By adding the voltages of the lower switches $\bar{u}_{k}$ :

$$
v_{\bar{u}_{k}}(t)=\left[v_{C_{k}}(t)-v_{C_{k-1}}(t)\right] u_{k}(t),
$$

the output voltage is obtained as

$$
\begin{aligned}
v_{s}(t) & =\sum_{k=1}^{n} v_{\bar{u}_{k}}(t) \\
& =\sum_{k=1}^{n}\left[v_{C_{k}}(t)-v_{C_{k-1}}(t)\right] u_{k}(t),
\end{aligned}
$$

with $v_{C_{0}}(t)=0$ and $v_{C_{n}}(t)=E$.

Finally, by regrouping expressions (10) to (13) in the state equations form, we obtain:

$$
\left\{\begin{array}{cl}
\dot{v}_{C_{1}} & =\frac{\left[u_{2}(t)-u_{1}(t)\right]}{C_{1}} i_{s}(t) \\
\dot{v}_{C_{2}} & =\frac{\left[u_{3}(t)-u_{2}(t)\right]}{C_{2}} i_{s}(t) \\
\vdots & \\
\dot{v}_{C_{n-1}} & =\frac{\left[u_{n}(t)-u_{n-1}(t)\right]}{C_{n-1}} i_{s}(t) \\
v_{s}(t) & =\sum_{k=1}^{n}\left[v_{C_{k}}(t)-v_{C_{k-1}}(t)\right] u_{k}(t)
\end{array}\right.
$$

Equations (14) shows that the multicell serial converter is a particular class of hybrid dynamical systems (HDS) (see [8] for a nice written of HDS, for multicell serial converter described as a HDS, see [9]).

\section{PROPOSED DIRECT CONTROL FOR 3 CELLS CHOPPER}

A PWM control-based allows a simple and effective control of the internal tensions, but only for the cases where the number of cells is prime. In addition, this control is based on an average model, which benefits the slow variations. It is desirable a valid control law for any number of cells allowing, at the same time, a faster convergence. In order to obtain these features the controllability of the multicell structure will be analyzed at first. After this, a sliding mode based control will be proposed.

\section{A. Internal Controllability}

The controllability describes the ability of an external input to move the internal state of a system from any admissible initial state to any other admissible final state in a finite time interval.

In the particular case of a multicellular converter it can be translated as follows: "Is it possible to find a n-uplet of finite time intervals $\delta t_{k}$ associated to $n$ commands $\boldsymbol{u}_{\boldsymbol{k}}$ so as to bring the system state $\boldsymbol{x}$ to a neighboring state $\boldsymbol{x}+\Delta \boldsymbol{x}$, for a given $\lambda^{*}$ output level voltage?". We can express this

\footnotetext{
*Under equilibrium conditions, the output level voltage can take $n+1$ values or discrete levels: $v_{s}=\lambda \frac{E}{n}$, where $\lambda$ is an integer number between 0 and $n$.
} 
question mathematically:

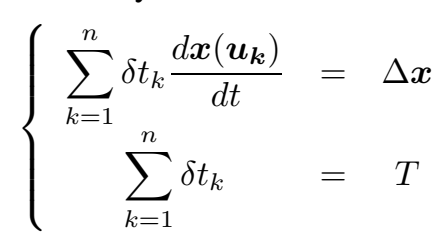

The "unidirectional flow of time" constraint must be added, that is to say:

$$
\delta t_{k} \geqslant 0
$$

From the hybrid time trajectory defined in [10] and using equation (10), a controllability condition of system (14) can also be expressed as a rank condition. For the sake of place, only the three cells converters are treated (figure 2).

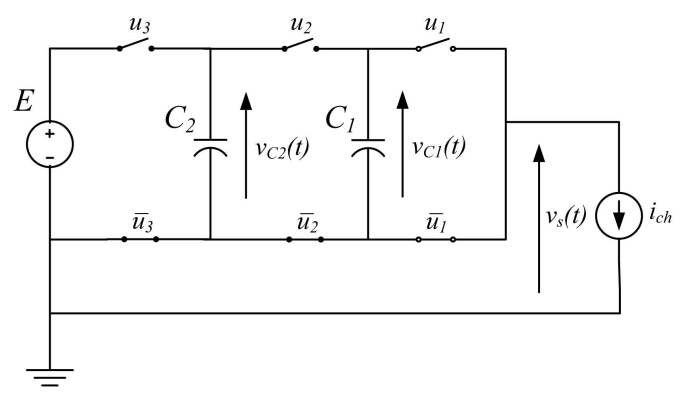

Fig. 2. 3-cells converter

Case 1: $\lambda=0$ or $\lambda=3$

In this case internal voltages (state variables) are not controllable (no capacitor is requested). The output voltage $v_{s}$ is equal to 0 or $E$, respectively for the two combinations of inputs $u_{3}=u_{2}=u_{1}=0$ or $u_{3}=u_{2}=u_{1}=1$ during $T$. We have $\dot{v}_{C_{1}}=0$ and $\dot{v}_{C_{2}}=0$. Then

$$
\operatorname{rank}\left[\begin{array}{ll}
0 & 0
\end{array}\right]=0
$$

Case $2: \lambda=1$

In this case, the output voltage $v_{s}=\frac{E}{3}$ for the three combinations of inputs $\left(u_{3}, u_{2}, u_{1}\right)=(0,0,1),\left(u_{3}, u_{2}, u_{1}\right)=$ $(0,1,0)$ and $\left(u_{3}, u_{2}, u_{1}\right)=(1,0,0)$ during $T$. Consequently the rank condition leads to

$$
\operatorname{rank}\left[\begin{array}{cc}
-\frac{i_{s}}{C_{1}} & 0 \\
-\frac{i_{s}}{C_{1}} & \frac{i_{s}}{C_{2}} \\
0 & -\frac{i_{s}}{C_{2}}
\end{array}\right]=2
$$

with $i_{s} \neq 0$.

Case $3: \lambda=2$

In this case, the output voltage $v_{s}=\frac{2 E}{3}$ for the three combinations of inputs $\left(u_{3}, u_{2}, u_{1}\right)=(0,1,1),\left(u_{3}, u_{2}, u_{1}\right)=$ $(1,0,1)$ and $\left(u_{3}, u_{2}, u_{1}\right)=(1,1,0)$ during $T$. Then the rank condition is obtained as

$$
\operatorname{rank}\left[\begin{array}{cc}
-\frac{i_{s}}{C_{1}} & 0 \\
-\frac{i_{s}}{C_{1}} & \frac{i_{s}}{C_{2}} \\
0 & -\frac{i_{s}}{C_{2}}
\end{array}\right]=2
$$

with $i_{s} \neq 0$.

The "unidirectional flow of time" condition is accomplished because the internal voltages can vary in both positive or negative directions by the action of switch commutations, so it is not necessary to have negative $\delta t_{k}$ coefficients $^{\dagger}$.

We can conclude that multicell converters are controllable, during $T$, for any $\lambda$ level different from 0 or 3 if, and only if, the current is different from zero .

\section{B. 3-cells chopper sliding mode based control}

In order to obtain the same voltage over each cell, the capacitor voltages must take the following values: $v_{C_{1}}=$ $E / 3$ and $v_{C_{1}}=2 E / 3$. These are the reference values for the capacitor voltages.

To satisfy this objective, we apply the first order sliding modes technique described in [11] The proposed manifolds are the following:

$$
\begin{aligned}
s_{1} & =v_{C_{1}}-v_{r e f_{1}} \\
& =\frac{1}{C 1} \int_{0}^{t}\left(u_{2}-u_{1}\right) i_{s}(\tau) d \tau-v_{r e f_{1}} \\
s_{2} & =v_{C_{2}}-v_{r e f_{2}} \\
& =\frac{1}{C 2} \int_{0}^{t}\left(u_{3}-u_{2}\right) i_{s}(\tau) d \tau-v_{r e f_{2}}
\end{aligned}
$$

Let us call $\left(u_{2}-u_{1}\right)=p_{1}$ and $\left(u_{3}-u_{2}\right)=p_{2}$. The derivatives of the manifolds are:

$$
\begin{aligned}
& \dot{s}_{1}=\frac{p_{1}}{C_{1}} i_{s}-\dot{v}_{r e f_{1}} \\
& \dot{s}_{2}=\frac{p_{2}}{C_{2}} i_{s}-\dot{v}_{r e f_{2}}
\end{aligned}
$$

Note that there are three inputs but two manifolds! This is because the inputs are "coupled": the input $u_{2}$ is "shared" between the capacitor $C_{1}$ and $C_{2} \cdot p_{1}$ and $p_{2}$ are not independent, therefore neither are the surfaces . This fact means that, in general, it is not possible to converge to both surfaces at the same time. When the control acts over one of the manifolds, the other one may keep invariant or must be "disturbed".

In order to achieve an effective control under these conditions, a priority over the surfaces must be taken into account. This is done by applying the algorithm shown in figure 3[12].

After the $\lambda$ output voltage level is decided (throught an independent algorithm), this value is compared to 0 and 3 . These are the non-controllable levels. If there is a match, the "non-controllable phase" is executed, otherwise, the "projection" phase. The "non-controllable phase" consists on the application of the actual $\lambda$ level during a half switching period.

The "projection" phase calculates the combination of switches which approximate the actual capacitor voltages to their references values. This is done by computing the projection (dot product) between $\dot{\boldsymbol{v}}_{\boldsymbol{C}_{\boldsymbol{k}}}$ and $\left[\boldsymbol{v}_{\boldsymbol{C} \boldsymbol{r} \boldsymbol{e}}-\boldsymbol{v}_{\boldsymbol{C}}\right]$.

$$
\dot{\boldsymbol{v}}_{\boldsymbol{C}_{\boldsymbol{p}}}: \dot{\boldsymbol{v}}_{\boldsymbol{C}_{\boldsymbol{k}}} / \max \left\{\dot{\boldsymbol{v}}_{\boldsymbol{C}_{\boldsymbol{k}}} \cdot\left(\boldsymbol{v}_{\boldsymbol{C} \boldsymbol{r} \boldsymbol{f}}-\boldsymbol{v}_{\boldsymbol{C}}\right)\right\}
$$

The $\dot{\boldsymbol{v}}_{C_{\boldsymbol{k}}}$ vector which provides the largest projection value, called $\dot{\boldsymbol{v}}_{C_{\boldsymbol{p}}}$ in equation (20), is applied during a time interval of $\frac{T_{s}}{3}$; this task is accomplished by choosing the correspondent switches combination.

†If $T$ is not large enough, one or more $\delta t_{k}$ may be negative. For the time, $T$ is not fixed at a predetermined value, just bounded. 


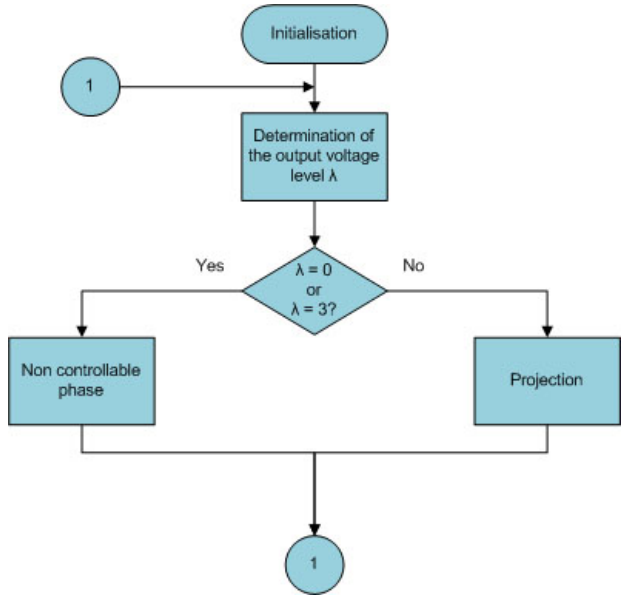

Fig. 3. Priority algorithm

As an example, consider the case where the output level voltage is the correspondent to the level $\lambda=1$, that is to say, $v_{s}=\frac{E}{3}$ (figure 4). Let's place the $\left[\boldsymbol{v}_{\boldsymbol{C} r e f}-\boldsymbol{v}_{\boldsymbol{C}}\right]$ vector at the origin of the system of coordinates. As we can see, the vector which provides the largest projection is the correspondent to the $(0,1,0)$ switch combination. So in the

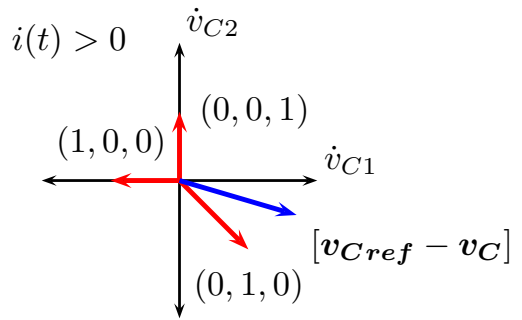

Fig. 4. Example of projection phase for $\lambda=1$

next $\frac{T_{s}}{3}$ time interval this combination will be applied. After that a new computation of the projection value is done (only in the cases when the actual phase is the "controllable" one) In this particular case, the two manifolds are modified at the same time. Supposing that the reference value is a constant:

$$
\begin{gathered}
\dot{s}_{1}=\frac{1}{C_{1}} i_{s} \\
\dot{s}_{2}=-\frac{1}{C_{2}} i_{s}
\end{gathered}
$$

Both capacitors voltages are approached to their reference values.

When the priority (value of the projections) of one the vectors $\dot{\boldsymbol{v}}_{C_{\boldsymbol{k}}}$ is the highest one, only one capacitor voltage will be approached to its reference.

After a certain transient period there will be two vectors $\dot{\boldsymbol{v}}_{C_{k}}$ which will have the same priority (the same projection value). From that moment the two switch combinations correspondent to these vectors will be applied consecutively. The surfaces $s_{1}$ and $s_{2}$ will converge to zero at the same time. During this transient period the commutation frequency will be $3 \frac{f_{s}}{2}$.
When the surfaces are zero, the three possible switch combinations will be applied. Under these conditions the switching frequency will be $f_{s}$.

The algorithm presented is designed to be used in converters of any number of cells.

\section{SIMULATION AND EXPERIMENTAL RESULTS}

In this section the simulation and experimental results will be presented in order to show the behavior of the proposed control.

\section{A. Simulation results}

The simulation parameters are the following:

- voltage source $E=300 \mathrm{~V}$

- current source $i_{s}=1 A$

- capacitances $C=33 \mu \mathrm{F}$

- $f_{s}=20 \mathrm{kHz}$

In figure 5 the capacitor voltages of a first simulation are shown, for initial values $v_{C_{1}}(0)=v_{C_{2}}(0)=0$ and output voltage $v_{s}=\frac{E}{3}(\lambda=1)$

In figure 5 (a) the temporal evolution of the capacitor voltages are shown.

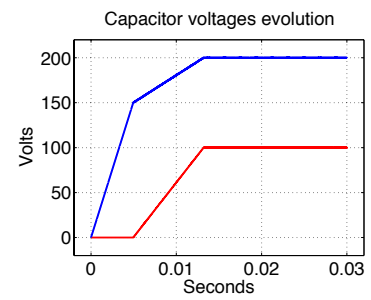

(a) Capacitor voltages

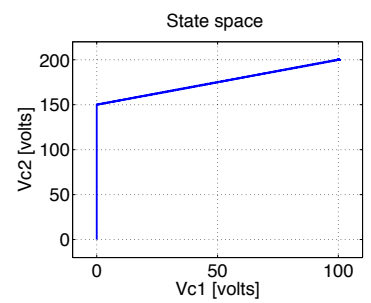

(b) State space
Fig. 5. Capacitor voltages for simulation 1

From zero to $5 \mathrm{~ms}$ the algorithm gives priority to the combination $\left(u_{1}, u_{2}, u_{3}\right)=(0,0,1)$ which lets the $v_{C_{2}}$ voltage evolve, only. From $5 \mathrm{~ms}$ to $13 \mathrm{~ms}$ the combinations $\left(u_{1}, u_{2}, u_{3}\right)=(0,0,1)$ and $\left(u_{1}, u_{2}, u_{3}\right)=(0,1,0)$ take the same priority, so the both are applied consecutively and the actual switching frequency is $3 \frac{f_{s}}{2}=30 \mathrm{kHz}$. At $13 \mathrm{~ms}$ the two capacitor voltages reach their reference values, hence the sliding mode is reached, and the three combinations are applied. From this moment, the switching frequency is $f_{s}=20 k H z$.

The three mentioned steps can be analyzed from the state space in figure $5(\mathrm{~b})$. When the combination $\left(u_{1}, u_{2}, u_{3}\right)=$ $(0,0,1)$ takes priority, the voltage of capacitor $C_{2}$ evolves from zero to $145 \mathrm{~V}$. Then, the combinations $\left(u_{1}, u_{2}, u_{3}\right)=$ $(0,0,1)$ and $\left(u_{1}, u_{2}, u_{3}\right)=(0,1,0)$ are applied consecutively. This is shown in detail in figure 6(a). Finally, when the sliding mode is reached, the three combinations are applied, that can be seen in the "triangular form" $\ddagger$ shown in figure 6(b). Note that, under ideal sliding mode conditions and for constant reference values, the sliding mode behavior is represented as a point in the state space.

\footnotetext{
$\ddagger$ The "triangular form" shows the presence of chattering, a phenomena present in all real sliding mode conditions due to the non-infinite switching frequency.
} 


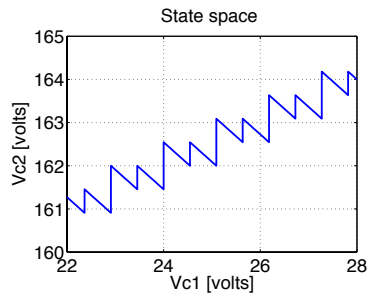

(a) Two vectors with the same priority

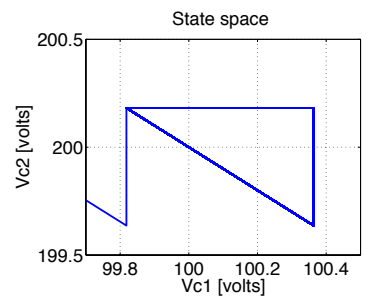

(b) Sliding mode behavior
Fig. 6. State space detail

The output voltage and the desired output level are shown in figure 7. As we can see, the desired output level $\lambda$

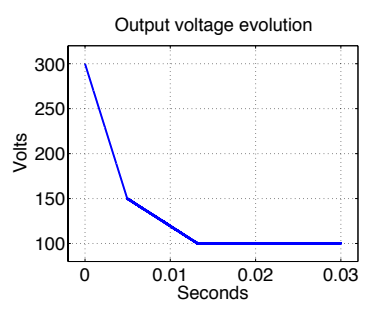

(a) Output voltage evolution

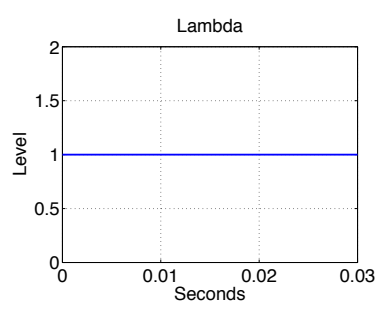

(b) Output level $\lambda$
Fig. 7. Output voltage and level of simulation 1

(computed as $\lambda=u_{1}+u_{2}+u_{3}$ ) is always one, but the correspondent output voltage is not reached until the capacitor voltages take their reference values at $13 \mathrm{~ms}$.

In order to show a more realistic behavior of the proposed control law, another simulation will be made. This time, the 3-cells structure will be configured as a half-bridge inverter and a RL load will be placed instead of a current source (figure 8). The switching frequency will be $f_{s}=10 \mathrm{kHz}$. An independent algorithm (based on sliding modes[12]), will control the output current and a sinusoidal perturbation will be added to the voltage source.

In the half-bridge inverter configuration the output voltage can take positive and negative values. Under equilibrium conditions these are: $\pm E / 6$ and $\pm E / 2$. The simulation parameters are:

- voltage source of $300 \mathrm{~V}$ with a $50 \mathrm{~Hz}$ sinusoidal perturbation of $10 \mathrm{~V}$ peak value.

- reference current: sinusoidal waveform of $1.5 \mathrm{~A}$ peak value and $200 \mathrm{~Hz}$.

- RL load: $R=33$ and $L=50 \mathrm{mH}$.

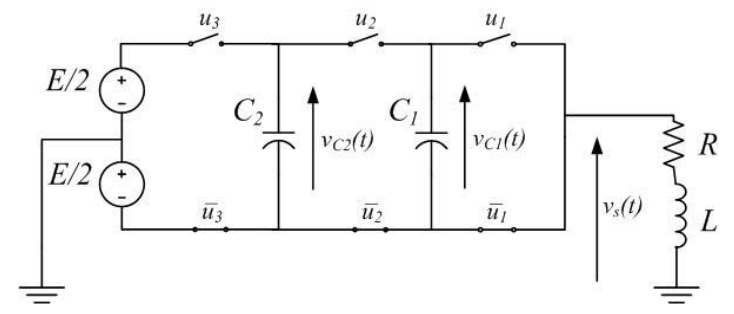

Fig. 8. Half-bridge inverter configuration associated to a RL load
The output current, its reference and the output voltage are shown in figure 9. It can be seen that, after a transient period,

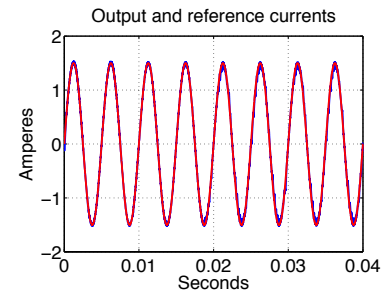

(a) Reference and output currents

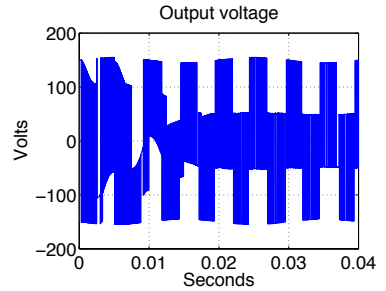

(b) Output voltage
Fig. 9. Current and output voltage of second simulation

the output voltage takes its four possible values: $\pm 50 \mathrm{~V}$ and $\pm 150 \mathrm{~V}$. Note that these output levels are affected by the sinusoidal perturbation of the voltage source.

In figure 10 the capacitor voltages and the correspondent state space are shown. It can be seen that, after a transient

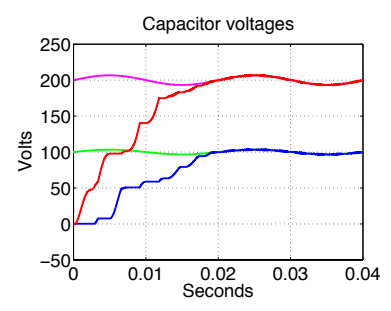

(a) Capacitor voltages

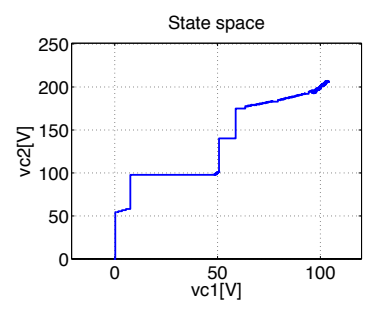

(b) State space
Fig. 10. Internal voltages of second simulation

period, both surfaces converge to their reference values at the same time, so the sliding mode is reached. As we can see in figure 10(b), there are different freedom degrees depending on the actual output voltage level. That's why the sliding mode condition is reached in a different way this time.

Performing a zoom over the state space we can see in detail the sliding mode behavior (figure 11). The three possible

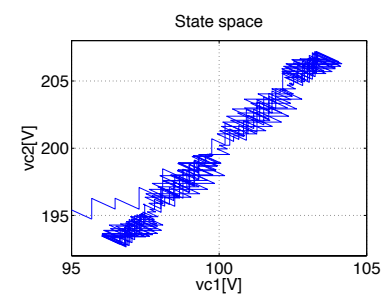

Fig. 11. Sliding mode behavior detail on state space

combinations for each $\lambda$ level are taken. In this case the reference values are not fixed, so the surfaces are variable ones, that is the reason why in sliding mode conditions there is no "triangular form" like in the first simulation (figure 6(b)). The switching frequency is $f_{s}=10 \mathrm{kHz}$ again.

Finally, in order to show the robustness of both control laws, another perturbation will be added: the value of the load resistance will vary between $\pm 100 \%$. The variation law follows a sinusoidal waveform with $100 \mathrm{~Hz}$ of frequency. In 
figure 12 the output current and the capacitor voltages are shown. As it can be seen, both of them converge rapidly to their reference values. The resistance variation doesn't perturb them.

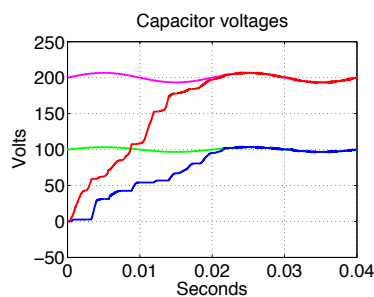

(a) Capacitor voltages

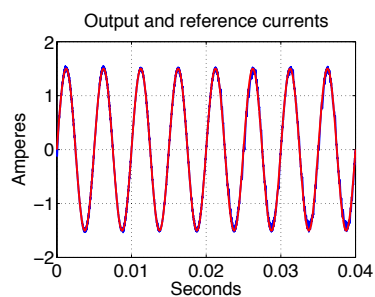

(b) Output current
Fig. 12. Capacitor voltages and output current for a variable load

\section{B. Experimental results}

In this sub-section some experimental results will be shown. The experimental set-up is the following:

- A 3-cells structure converter is used. The capacitor values are $33 \mu F$.

- The power supply $E$ is a $60 \mathrm{~V}$ source.

- A RL load is connected to the output. It consists of an $48 \mathrm{mH}$ inductance and a $50 \Omega$ resistance.

- The switching frequency is $f_{s}=6.6 \mathrm{kHz}$.

- The sampling frequency is $33 k H z$.

1) Experimental results for priority algorithm: The following tests correspond to the current control of a RL load. The algorithm used for this purpose will not be detailed in this paper (see[12]), it is relevant to mention that this control is based on sliding modes, thus the presence of chattering will be noted at the output.

The first test corresponds to a chopper configuration. A $0.5 A$ current reference is used. The results are shown in figure 13 . The output current and the capacitor voltages are

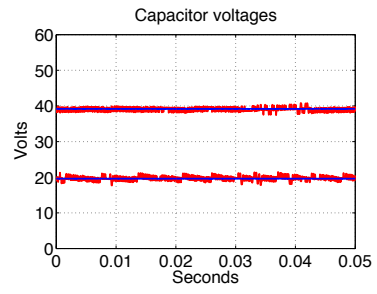

(a) Capacitor voltages

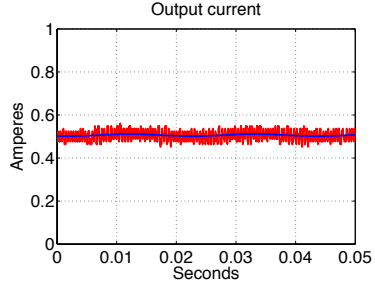

(b) Load current
Fig. 13. Experimental results for a constant reference current

coincident to their reference values except for the presence of the chattering phenomenon. This effect can be reduced by decreasing the current or by augmenting the switching frequency.

The second test (figure 14) corresponds to a half-bridge inverter. In this case a sinusoidal reference current of $300 \mathrm{~Hz}$ frequency and $0.5 \mathrm{~A}$ peak value is used. Again, the capacitor voltages and the load current are coincident to their reference values. The chattering is variable this time: the larger current values, the larger chattering.

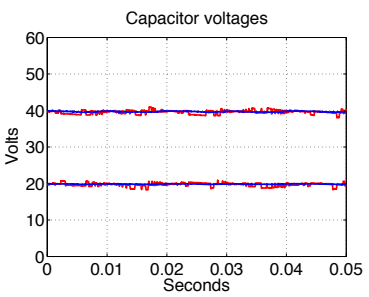

(a) Capacitor voltages

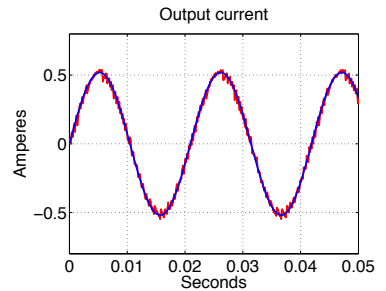

(b) Load current
Fig. 14. Experimental results for a sinusoidal reference current

\section{CONCLUSION}

In this paper a direct sliding mode control algorithm applied to a flying capacitor converter has been presented and developed. It has been showed that the proposed direct control ensures a good convergence of the voltages across the flying capacitors under fast variation of the input voltage. Furthermore an optimal steady-state trajectory is obtained according to the adjacency rules of the power switches. The simulation and experimentation results affirm a good performance of the proposed direct sliding mode control.

\section{REFERENCES}

[1] Erickson, R., D. Maksimovic, "Fundamentals of Power Electronics", Second Edition, Kluwer Academic Publishers, Dordrecht, The Netherlands, p. 576., 2001.

[2] T. Meynard and H. Foch, "Multilevel choppers for high voltage applications", EPE J., vol. 2, no. 1, pp. 4550, Mar. 1992.

[3] T. Meynard and H. Foch, "Electronic device for electrical energy conversion between a voltage source and a current source by means of controllable switching cells", European Patent 92/916336.8, July 8 , 1992.

[4] T. Meynard, M. Fadel, and N. Aouda, "Modeling of multilevel converters”, IEEE Trans. Ind. Electron., vol. 44, pp. 356364, June 1997.

[5] Gateau, G., "Contribution á la commande des convertisseurs statiques multicellulaires: Commande non linéaire et commande floue", $\mathrm{Ph} . \mathrm{D}$. dissertation, INP, Toulouse, France, 1997.

[6] Gateau, G., M. Fadel, P. Maussion, R. Bensaid and T. Meynard, "Multicell converters: active control and observation of flying-capacitor voltages", IEEE Trans. on Industrial Electronics, vol. 49, no. 5, pp 9981008 , October 2002.

[7] Béthoux, O., "Commande et détection de défaillance dun Convertisseur Multicellulaire Série”, PhD thesis, Université de Cergy-Pontoise, 2005.

[8] R. Goebel, R. Sanfelice, and A.R. Teel. "Hybrid dynamical systems". IEEE Control Systems Magazine, 29(2):28-93, 2009.

[9] F. Bejarano, M. Ghanes and J.B. Barbot, "Observability and Observer Design for Hybrid Multicell Choppers", International Journal of Control, vol 83, p. 617 - 632, 2010.

[10] Lygeros J, Johansson HK, Sinć SN, Zhang J, Sastry SS. Dynamical properties of hybrid automata. IEEE Transactions on Automatic Control; 48(1):2-17, 2003

[11] Perruquetti, W., J. P. Barbot, Sliding mode Control in engineering, New York: Marcel Dekker, 2002.

[12] Amet, L., “Commande et réalisation d'un Convertisseur Multicellulaire”, ENSEA, 2010. 